\title{
A novel running annuloplasty suture technique for robotically assisted mitral valve repair
}

\author{
Tomislav Mihaljevic, MD, ${ }^{\mathrm{a}}$ Craig M. Jarrett, MD, MBA, ${ }^{\mathrm{a}}$ A. Marc Gillinov, MD, and
}

Eugene H. Blackstone, MD, ${ }^{\mathrm{a}, \mathrm{b}}$ Cleveland, Ohio

Longer operative times necessary for robotic mitral valve (MV) repair have in part slowed its adoption. A significant portion of operative time is dedicated to placement of the annuloplasty ring, which is usually anchored with individual mattress sutures that require time-consuming instrument tying. We have developed an alternative technique

\footnotetext{
From the Department of Thoracic and Cardiovascular Surgery a and Department of Quantitative Health Sciences, ${ }^{\mathrm{b}}$ Cleveland Clinic, Cleveland, Ohio.

Disclosures: Dr Mihaljevic is a consultant for Intuitive Surgical Inc (Sunnyvale, Calif), St Jude Medical Inc (St Paul, Minn), and Edwards Lifesciences (Irvine, Calif). Dr Gillinov is a consultant for Edwards Lifesciences and St Jude Medical, receives research support from St Jude Medical and Medtronic (Minneapolis, Minn), and has equity in Viacor (Wilmington, Mass)

Received for publication Nov 24, 2009; accepted for publication Dec 7, 2009; available ahead of print March 2, 2010

Address for reprints: Tomislav Mihaljevic, MD, Department of Thoracic and Cardiovascular Surgery, Cleveland Clinic, 9500 Euclid Avenue, Cleveland, OH 44125 (E-mail: mihaljt@ccf.org).

J Thorac Cardiovasc Surg 2010;139:1343-4 $0022-5223 / \$ 36.00$

Copyright (C2010 by The American Association for Thoracic Surgery doi:10.1016/j.jtcvs.2009.12.023
}

using running annuloplasty sutures that requires fewer steps than conventional techniques and could reduce operative times. We sought to compare the safety and effectiveness of this novel running annuloplasty suture technique with the conventional interrupted annuloplasty suture technique.

\section{OPERATIVE TECHNIQUE}

All patients underwent MV repair by triangular leaflet resection and insertion of a flexible annuloplasty band (Cosgrove Edwards, Edwards Lifesciences, Irvine, CA). For the interrupted suture technique, ten to twelve 2-0 braided polyester sutures are used to secure the annuloplasty ring in the standard fashion. For the running suture technique, three 2-0 braided polyester sutures (Ticron, Covidien, MA) are used to secure the annuloplasty ring as follows. After the ring is introduced into the left atrium, the first suture (16 $\mathrm{cm}$ in length) is passed through the ring, through the right trigone, and then back through the ring. The suture is
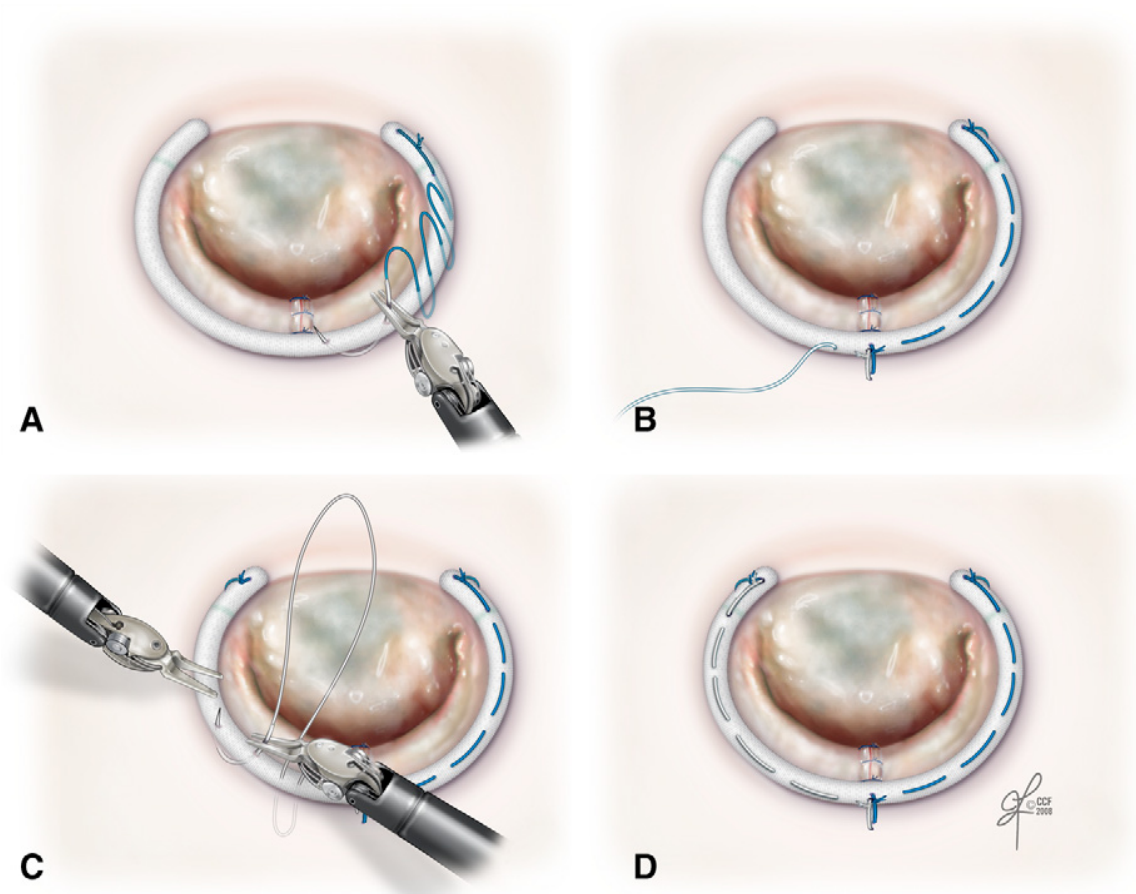

FIGURE 1. Schematic diagram of running annuloplasty suture technique. A, First suture is tied at the right trigone and run clockwise. B, Second suture is tied at the mid-portion of the annulus and the tail is tied to the first suture. C, Second suture is run clockwise. D, Third suture is tied at the left trigone and the tail is tied to the second suture. 
TABLE 1. In-hospital outcomes by annuloplasty suture technique

\begin{tabular}{|c|c|c|c|}
\hline Variable & $\begin{array}{l}\text { Interrupted }(n=50) \\
\text { Median }\left(\mathbf{C L}^{*}\right)\end{array}$ & $\begin{array}{c}\text { Running }(\mathbf{n}=\mathbf{5 0}) \\
\text { Median }\left(\mathbf{C L}^{*}\right)\end{array}$ & $\boldsymbol{P}$ \\
\hline \multicolumn{4}{|l|}{ Operative times } \\
\hline $\begin{array}{l}\text { Procedure (wheels in to } \\
\text { wheels out) }\end{array}$ & $412(344-490)$ & $374(325-451)$ & .01 \\
\hline Cardiopulmonary bypass & 139 (109-180) & $107(91-151)$ & .0003 \\
\hline Aortic occlusion & $100(75-133)$ & $81(62-110)$ & .0008 \\
\hline Variable & $\begin{array}{c}\text { Interrupted }(n=49 \dagger) \\
\text { No. }(\%)\end{array}$ & $\begin{array}{l}\text { Running }(n=49 \dagger) \\
\text { No. }(\%)\end{array}$ & $P$ \\
\hline \multicolumn{4}{|l|}{ Postoperative MR severity } \\
\hline $\begin{array}{l}1+ \\
2+\end{array}$ & $\begin{array}{c}44(90) \\
4(8) \\
1(2)\end{array}$ & $\begin{array}{c}42(86) \\
6(12) \\
1(2)\end{array}$ & .9 \\
\hline
\end{tabular}

$M R$, Mitral regurgitation; $C L$, confidence limit. *Confidence limits are equivalent to 15 th and 85 th percentiles for consistency with \pm 1 standard deviation. $\dagger$ Postoperative MR severity was missing for 1 patient in each cohort.

then tied down and run clockwise to the midportion of the ring (Figure 1, A). The second suture (14 cm in length) is then passed through the ring, through the midportion of the annulus, and then back through the ring. This second suture is tied down, and the tail is used to secure the first suture (Figure 1, B). The second suture is then run clockwise to the left trigone (Figure 1,C). The third suture ( $9 \mathrm{~cm}$ in length) is passed through the ring, through the left trigone, and then back through the ring. This third suture is tied down, and the tail is used to secure the second suture (Figure 1,D).

\section{CLINICAL SUMMARY}

From January 2008 to July 2008, 100 patients with mitral regurgitation (MR) caused by myxomatous degeneration underwent attempted robotic MV repair by posterior leaflet resection and annuloplasty; patients who underwent additional chordal procedures were excluded. Interrupted annuloplasty sutures were used in the first 50 consecutive patients, and running annuloplasty sutures were used in the second 50 consecutive patients. MV repair was achieved in all patients. Median procedure time (wheels in to wheels out) was reduced by 38 minutes in patients with running annuloplasty sutures (Table 1). The use of running annuloplasty sutures resulted in a significant reduction of median cardiopulmonary bypass time (32 minutes less) and median aortic occlusion time (19 minutes less) (Table 1). There were no deaths or in-hospital reoperations for failed repair. Postoperative MR grades were similar between groups (Table 1).

\section{DISCUSSION}

Various methods have been used to secure prosthetic annuloplasty rings in robotically assisted MV repair. ${ }^{1,2}$ Rings typically are secured with 10 to 12 interrupted sutures or nitinol U-clips, with operative times that substantially exceed those of MV repairs performed through complete sternotomy or conventional minimally invasive approaches. ${ }^{1,2}$
Our technique takes advantage of the increased dexterity of robotic instruments, which permits the use of running sutures for the placement of the annuloplasty band. The use of 3 sutures of different lengths to secure the annuloplasty ring is the empiric result of attempts to expedite the process of annuloplasty through reductions in suture material exchange, time-consuming knot tying, and assistance from the bedside surgeon. We believe the use of 2 running sutures and 1 anchoring suture presents the optimal mix of fixation and fewest steps. Running a single suture the entire length of the annulus would provide 1 less independent point of fixation and require a longer suture that is more difficult to maneuver in the small atrial cavity. On the other hand, using more than 2 running sutures unnecessarily increases the number of steps.

\section{CONCLUSIONS}

The running annuloplasty suture technique we describe decreases operative times without sacrificing short-term outcomes. The significant reduction in cardiopulmonary bypass and aortic crossclamp times as a result of this technique makes operative times for robotic surgery comparable to those of conventional approaches ${ }^{3-5}$ and could lead to greater adoption of robotically assisted MV repair in the future.

\section{References}

1. Chitwood WR Jr, Rodriguez E, Chu MW, Hassan A, Ferguson TB, Vos PW, et al. Robotic mitral valve repairs in 300 patients: a single-center experience. $J$ Thorac Cardiovasc Surg. 2008;136:436-41.

2. Murphy DA, Miller JS, Langford DA, Snyder AB. Endoscopic robotic mitral valve surgery. J Thorac Cardiovasc Surg. 2006;132:776-81.

3. Loulmet DF, Carpentier A, Cho PW, Berrebi A, d'Attellis N, Austin CB, et al. Less invasive techniques for mitral valve surgery. J Thorac Cardiovasc Surg. 1998;115:772-9.

4. McClure RS, Cohn LH, Wiegerinck E, Couper GS, Aranki SF, Bolman RM 3rd, et al. Early and late outcomes in minimally invasive mitral valve repair: an eleven-year experience in 707 patients. J Thorac Cardiovasc Surg. 2009;137:70-5.

5. Saunders PC, Grossi EA, Sharony R, Schwartz CF, Ribakove GH, Culliford AT, et al. Minimally invasive technology for mitral valve surgery via left thoracotomy: experience with forty cases. J Thorac Cardiovasc Surg. 2004;127:1026-32. 